\title{
Veredas da leitura literária para a primeira infância: narrativas autobiográficas de uma escritora cearense
}

\author{
Literary Reading path for early childhood: autobiographic narratives from \\ a female writer cearense
}

\author{
Caminos de lectura literaria para la primera infancia: narraciones \\ autobiográficas de uma escritora cearense
}

\author{
Ana Maura Tavares dos Anjos ${ }^{1}$
}

\begin{abstract}
Resumo
A narrativa literária possibilita ao leitor infantil, através da arte, a compreensão sobre as experiências da vida em sua complexidade. Desse modo, o presente trabalho de natureza qualitativa situa-se no âmbito da Pesquisa (auto)biográfica em Educação e tem como método de investigação a narrativa autobiográfica para a constituição do corpus da pesquisa. Nesse sentido, objetivamos dialogar sobre o letramento literário a partir de minha narrativa autobiográfica como escritora de obras de literatura infantil. O estudo evidencia a importância das políticas públicas para o letramento e para a identificação, valorização e divulgação do trabalho de escritores e artistas cearenses. Os livros da coleção 'De casa para a escola' têm salientado a literatura como caminho profícuo para o desenvolvimento do letramento literário, da formação de valores e apontam veredas para o trabalho com o desenvolvimento de habilidades socioemocionais na primeira infância na inter-relação entre família e escola.
\end{abstract}

Palavras-chave: Letramento literário; Narrativa autobiografia; Mulher.

\section{Resumen}

La narrativa literaria permite al lector infantil, a través del arte, comprender las experiencias de la vida en su complejidad. De esta forma, el presente trabajo de naturaleza cualitativa se ubica dentro del alcance de la Investigación (auto) biográfica en Educación y tiene como método de investigación la narrativa autobiográfica para la constitución del corpus de investigación. En este sentido, nuestro objetivo es dialogar sobre la alfabetización literaria desde mi narrativa autobiográfica como escritor de obras de literatura infantil. Destaca la importancia de las políticas públicas para la alfabetización y para la identificación, valoración y difusión del trabajo de escritores y artistas. Los libros de la colección "Del hogar a la escuela" han destacado la literatura como un camino fructífero para el desarrollo de la alfabetización literaria, la formación de valores y señalan caminos para trabajar con el desarrollo de habilidades socioemocionales en la primera infancia.

Palabras clave: Alfabetización literaria; Narrativa autobiográfica; Mujer.

\begin{abstract}
The literary narrative allows the child reader, through art, to understand the experiences of life in its complexity. In this way, the present work of qualitative nature is ubiquitous within the scope of (auto) biographical Research in Education and as a method of investigation of the autobiographical narrative for the constitution of the research corpus. In this sense, our objective is to talk about literary literacy from my autobiographical narrative as a writer of children's literature. It highlights the importance of public policies for literacy and for the identification, valuation and diffusion of the work of writers and artists. The books of the collection "I left the school" have

\footnotetext{
${ }^{1}$ Doutoranda em Educação; Mestra em Educação; Universidade Federal do Rio Grande do Norte - UFRN, Natal, Rio Grande do Norte, Brasil; maurinhaanjos@ hotmail.com.
} 
highlighted literature as a fruitful way for the development of literary literacy, the formation of values and the ways to work with the development of socioemotional skills in early childhood.

Keywoords: literary literacy; autobiographical narrative; Woman.

\section{Tessituras iniciais}

Perguntaram-me: o que fazer para criar o hábito da leitura? Respondo: "Nada. Não se deve criar o hábito de leitura. Hábito tem a ver com cortar as unhas, tomar banho (...) Os hábitos produzem ações automáticas (...) O que há de se fazer é ensinar as crianças a amar os livros. (ALVES, 2014, p. 120)

As narrativas literárias provocam sedução nas crianças desde a mais tenra idade. Ainda no útero da mãe, a criança escuta narrativas. O som é o primeiro contato da criança com as histórias e a imagem nos livros é um convite para o universo da arte literária, para o desejo de ler. Mas como as crianças aprendem a desejar? Através da observação do vínculo que os adultos estabelecem com a prática da leitura, com o letramento literário. Dessa forma, um viés de reflexão epistemológica e prática para o desenvolvimento do letramento literário é ensinar a amar os livros, como enfatiza Rubem Alves (2014) na epígrafe de abertura de nosso diálogo.

O letramento literário, tem como objetivo principal formar leitores partícipes, críticos, capazes de vislumbrar e compreender parte do mundo, através da arte literária, um componente importante para o desenvolvimento do pensamento crítico por meio das narrativas. Nesse sentido nos indagamos: como favorecer o desenvolvimento do letramento literário na primeira infância? A construção argumentativa desse trabalho objetiva dialogar sobre o letramento literário a partir de minha narrativa autobiográfica como escritora de obras de literatura infantil.

Falar de letramento literário nos conduz ao diálogo crítico-reflexivo sobre a função da literatura e suas nuances quanto ao desenvolvimento e a aprendizagem da criança. As crianças nascem inseridas em uma sociedade marcada pela escrita, ou seja, uma sociedade grafocêntrica e, desde a mais tenra idade, fazem uso de práticas sociais em contextos de letramento na interação com os adultos nas mais variadas situações do cotidiano.

Desde muito cedo, ao ouvirem histórias e presenciarem o uso da escrita em diversas situações como anotações de uma lista de compras, uso de mensagens em redes sociais, as crianças, constroem conceitos e habilidades sobre o sistema de escrita e seus usos sociais.

Encontrar uma definição precisa de leitura não é fácil, uma vez que essa palavra apresenta diversos significados. No dicionário Aurélio (2000), é possível encontrar o seguinte 
conceito: ato, arte ou hábito de ler; aquilo que se lê; operação de percorrer; em meio físico, sequencias de marcas codificadas que representam informações registradas, e reconvertê-las à forma anterior como imagens, sons, dados para processamento.” Mas como a criança pequena internaliza?

A leitura é uma pratica que requer aprendizagem, ela não é simplesmente o ato de ler, ela é um comportamento, uma habilidade, uma tecnologia cuja aquisição envolve fatores cognitivos, socioculturais e emocionais apreendidos na interação social. Para desenvolver o hábito de ler, uma das condições basilares é o prazer e é aqui que a literatura com expressão artística e linguagem humana delineia o gozo por ouvir, contar e ler histórias.

Nossa instigação de natureza qualitativa fez uso da narrativa autobiográfica como método de investigação. Entendemos que, do ponto de vista epistemológico e metodológico de formação de professores, os saberes advindos da experiência, ou seja, a hermenêutica da prática, como enfatiza Passeggi (2016) são elementos formativos e autoformativos.

Desse modo, encontramos ancoradouro nos pressupostos da Pesquisa (auto)biográfica em Educação com Passeggi (2016) e as pesquisas vinculadas ao Grupo Interdisciplinar de Pesquisa, Formação, Autobiografia, Representações e SubjetividadesGRIFARS/UFRN/CNPq que está inserido na Linha de pesquisa Estudos Sociohistóricos e Filosóficos do Programa de Pós-Graduação em Educação - PPGEd/UFRN, cujo movimento autobiográfico no Brasil, é influenciado por pesquisadores internacionais no movimento socioeducativo das histórias de vida e formação, com Pierre Dominicé, por Antônio Nóvoa em Portugal na década de 1980 no âmbito da formação permanente, na França com Christine Dolory-Momberger, Marie-Christine Josso entre outros.

O texto está organizado em dois eixos que se articulam: reflexão teórica sobre letramento literário e sua relação com as minhas veredas de escrevivências literárias que (re)inventam a formação de professores no âmbito da literatura e sua interface com a solidificação de relações mais saudáveis em tempos de "fragilidade dos laços humanos" (BAUMAN, 2004).

2. LETRAMENTO LITERÁRIO: caminhos e possibilidades para o desenvolvimento da leitura desejante e reflexões socioemocionais

Conforme Barthes (2004), a leitura desejante é marcada pelo envolvimento do leitor com texto. Através da leitura literária, a criança é "deportada ao imaginário", se desvincula do 
real e emerge em sua inteireza no texto, ou seja, o corpo e as emoções do sujeito-leitor entram em contato com a narrativa. A leitura literária permite a construção de significados a partir do texto,

o texto deve poder, tanto do ponto de vista sociológico quanto do psicológico, descontextualizar-se de maneira a deixar-se recontextualizar numa nova situação: é o que justamente faz o ato de ler. Essa libertação em relação ao autor possui seu equivalente por parte daquele que recebe o texto. Diferentemente da situação dialogal, onde o vis-à-vis é determinado pela situação mesma do discurso, o 'discurso escrito suscita para si um público que, vitualmente, se estende a todo aquele que sabe ler. A escrita encontra, aqui, seu mais notável efeito: a libertação da coisa escrita relativamente à condição dialogal do discurso. O resultado é que a relação entre escrever e ler não é mais um caso particular da relação entre falar e ouvir. (RICOUER, 1990, p.53)

Nessa lógica, a criança constrói significados, interpreta signos e constitui o "ethos" infantil do leitor desejante na sociedade atual, mas para a formação de leitores desejantes é preciso o contato, a experiência com obras literárias que despertem a fantasia e o prazer. Minhas primeiras experiências com a literatura aconteceram nas escolas, por onde passei, em salas de leitura que avolumavam exemplares a espera de leitores. Foi na escola que nasceu o meu desejo pelo saber pela leitura.

As crianças vão progressivamente ampliando seu vocabulário e construindo narrativas na mediação e na interação com os adultos nos espaços de educação escolar e nãoescolar. Assim, a leitura desejante perpassa o desenvolvimento de repertórios comportamentais, que tem os adultos como mediadores de referência, ou seja, além das crianças é preciso conquistar os adultos com os quais as crianças convivem, promovendo espaços intergeracionais para a inclusão das narrativas de tradição oral das pessoas na comunidade na escola.

A leitura desejante se torna possível pela interação entre os elementos textuais e o leitor. Quanto maior for o conhecimento entre eles, maior a probabilidade de êxito na leitura, mais sólida será a tríade amorosa, como afirma Reyes (2011), entre o leitor, o texto e o ato de ler que é permeado por aspectos subjetivos, cognitivos, afetivos, contextuais e históricos.

Para Freire (1989), a leitura do mundo precede ou deve vir antes da leitura do texto escrito. $\mathrm{O}$ ato de ler é um exercício de indagação de reflexão crítica, uma habilidade que potencializa o caminho para a autocrítica acerca da natureza historicamente construída de sua própria experiência" (FREIRE, 2015, p. 45). Logo, ler seria compreender aspectos da conjuntura social e sua relação com a existência. 
Ler ultrapassa o procedimento de decodificar símbolos. Compreender o que se lê depende de características do leitor, além das particularidades do próprio texto. Assim, as formas de linguagem que ele domina, o conhecimento de mundo, seus propósitos e seus esquemas conceituais facilitam ou dificultam a compreensão. Ler não se trata simplesmente de extrair informações da escrita, decodificando-a letra palavra por palavra. Trata-se de uma atividade que implica, necessariamente, compreensão na qual os sentidos começam a ser constituídos antes da leitura propriamente dita.

De acordo com Soares (2003), leitura é entendida como um processo de produção de sentimento que se dá a partir de interações sociais ou relações dialógicas que acontecem entre dois sujeitos: o autor do texto e o leitor. Esse processo depende, fundamentalmente, do uso de estratégias cognitivas de leitura, a mesma inclui fazer previsões sobre o texto, de construir e refletir sobre o significado do que foi lido e tirar conclusões sobre o assunto.

Por outro lado, essas habilidades são desenvolvidas à medida que o leitor, faz uso da leitura e desse modo constrói sentido sobre o texto. Para formação de leitores, a escola deve oportunizar ambiência que favoreça o estímulo do pensamento, da criatividade e da criticidade desde os seus primeiros contatos com as narrativas orais e com os livros, pois a literatura possibilita ricas situações de oralidade para a criança.

Um leitor competente "sabe construir um sentido nas obras lidas" COLOMER, 2007, p.31) sendo capaz de selecionar, dentre os gêneros que circulam socialmente, aqueles que podem atender a sua necessidade, anseios e desejos. Essa ideia já era identificada na década de 1990.

Formar um leitor competente supõe formar alguém que compreenda o que lê; que possa aprender a ler também o que não está escrito, identificando elementos implícitos; que estabeleça relações entre o texto que lê e outros textos já lidos; que saiba que vários sentidos podem ser atribuídos a um texto; que consiga justificar e validar a sua leitura a partir da localização de elementos discursivos (PCN's, Língua Portuguesa, ensino fundamental, 1998, p. 41).

A leitura literária pressupõe o desenvolvimento do leitor competente. Esse leitor é alguém que possui e transcende os conhecimentos informativos e o aparato instrumental para análise instrumental.

Soares (2003) assevera que um leitor competente só pode constituir-se mediante uma prática constante de leitura de textos que circulam socialmente. Para tornar os alunos bons leitores para desenvolver muito mais do que a capacidade de ler, o gosto e o compromisso com 
a leitura, é preciso mobilizar as crianças tornando-as confiante e motivadas a ler. Uma prática de leitura que não desperte e cultive o desejo de ler não é uma prática pedagógica eficiente para o letramento.

O uso do termo letramento ganha notoriedade a partir de Soares (2003). Traduzido do inglês literacy diz respeito ao "estado ou condição que adquire um grupo social ou indivíduo como consequência de ter-se apropriado da escrita." (SOARES, 2003, p.18) e fazer uso da leitura e da escrita nos diversos contextos sociais. Para ela são muitas as "facetas" do letramento: imersão das crianças na cultura escrita, conhecimento e interação com diferentes tipos e gêneros de material escrito.

Destarte, o letramento literário requer condições para a pratica de leitura que transcenda a apropriação do sistema de escrita e garanta o contato com o gênero literário de forma prazerosa. A leitura literária deve proporcionar o deleite sem 'pedagogismos', sem didatizar a apreciação estética da obra artística. Esse viés é determinante para o desenvolvimento da prática e do gozo, do desejo e a formação de leitores autônomos.

Nesse cenário, a literatura infantil se configura com dimensão artística que possibilita as crianças, o desenvolvimento da imaginação, criatividade, múltiplas linguagens e expressão de pensamentos, sentimentos e a construção e ressignificação de sentidos sobre o mundo que a cerca e sobre si mesmo. Se letrar significa se apropriar suficientemente da escrita e da leitura e usa-las no cotidiano, os livros de literatura devem fazer parte constante desse processo, pois trazem consigo múltiplas possibilidades de trabalhos nos diversos campos de experiência e de formação humana.

A literatura permite à criança a transposição entre as dimensões do real e do imaginário permitindo a ampliação de horizontes, conhecimentos e capacidade crítica e inventiva. Daí a importância da democratização do acesso ao livro e à leitura como ação educativa fundamental na formação e no desenvolvimento das crianças. Quanto mais cedo o livro entrar na vida da criança, em sua casa, no ciclo de interesses e de desejo mais fácil será para ela, sentir prazer em ler e desenvolver a fruição em leitura e a compreensão do sistema de escrita.

Texto de prazer: aquele que contenta, enche, dá euforia; aquele que vem da cultura, não rompe com ela, está ligado a uma prática confortável da leitura. Texto de fruição: aquele que põe em estado de perda, aquele que desconforta (talvez até um certo enfado), faz vacilar as bases históricas, culturais, psicológicas, do leitor, a consistência de seus gostos, de seus valores e de suas lembranças, faz entrar em crise sua relação com a linguagem. Ora, é um sujeito anacrônico aquele que mantém os dois textos em 
seu campo e em sua mão as rédeas do prazer e da fruição, pois participa ao mesmo tempo e contraditoriamente do hedonismo profundo de toda cultura. (BARTHES, 1979, p.21-22)

A arte literária é um instrumento de cidadania, de linguagem e de formação, através dela acessamos instâncias psíquicas que possibilitam a ressignificação de conceitos, experiências e sentimentos, refletimos sobre os conflitos humanos nos identificando com personagens que falam sobre nós, sobre o humano em sua complexidade e antagonicamente permite ao leitor o prazer e fruição.

A formação dos alunos "como cidadãos da cultura escrita é um dos principais objetivos da escola" (COLOMER, 2007, p. 30) A formação de cidadãos da cultura escrita incide na incumbência da escola em formar leitores competentes, produtores de sentido. O "[..] objetivo da formação literária é, em primeiro lugar, o de contribuir para a formação da pessoa, uma educação que aparece ligada indissoluvelmente à construção da sociabilidade" (COLOMER, 2007, p.31) e ao contato com a diversidade social e cultural e desse modo ao posicionamento político, ético do homem na realidade.

Mas, como solidificar as relações em uma época caracterizada pela liquidez da sociedade e das relações por meio da literatura infantil? Zigmunt Bauman (1925-2017), sociólogo e filósofo polonês, caracteriza as relações entre os indivíduos nos tempos atuais como "relações que escorrem pelo vão dos dedos". Segundo o seu conceito de "relações líquidas", de acordo com Bauman (2004), as relações humanas são frágeis, facilmente se desfazem com a mesma facilidade com as quais foram feitas.

A Escola está imersa no desafio de propor ações educativas que superem a dicotomia entre o sujeito da razão e o sujeito da emoção e possibilite o trabalho de aperfeiçoamento de habilidades socioemocionais que transponham o estímulo da cognição e instigue a inteligência emocional, uma vez que toda inteligência é emocional, pois o homem é um ser de emoções. Conforme Goleman (1997), o ensino brasileiro pode se beneficiar com a introdução, no currículo escolar, de programas de aprendizagem que, além das disciplinas tradicionais, inclua ensinamentos para uma aptidão pessoal fundamental - a alfabetização emocional.

Desde a mais tenra idade, nas primeiras interações sociais, a criança constrói os pilares fundantes de sua dimensão socioafetiva. Wallon (1879-1962), teórico francês, ressalta que a vida psíquica é formada por três dimensões - motora, afetiva e cognitiva -, que coexistem e atuam de forma integrada na formação da criança. Para ele, a criança nasce com o aparato 
biológico que a capacita a desenvolver habilidades como por exemplo a fala, porém, a condição biológica não é suficiente, é preciso que haja interação social. Ou seja, é preciso a mediação para que o indivíduo transforme suas estruturas psíquicas. Nessa direção é importante que o currículo escolar disponha de tempo pedagógico e espaço dialógico para inserção de aprendizagens relacionadas ao autoconhecimento, controle das emoções, empatia, respeito, solidariedade.

Dito isso, e atentas aos dispositivos legais, identificamos que desde a Constituição Federal de 1988 em seu Art. 205, a educação é compreendida em seu aspecto de integralidade do ser, com a perspectiva de materialização de tal objetivo através do currículo, conforme aponta o Art. 210: "Serão fixados conteúdos mínimos para o ensino fundamental, de maneira a assegurar formação básica comum e respeito aos valores culturais, nacionais e regionais.”

A Lei de Diretrizes e Bases da Educação Nacional n 9394/96 reafirma as prerrogativas apresentadas na Constituição acerca da educação em uma perspectiva de formação integral do indivíduo: Art. 1 "A educação abrange os processos formativos que se desenvolvem na vida familiar, na convivência humana, no trabalho, nas instituições de ensino e pesquisa, nos movimentos sociais e organizações da sociedade civil e nas manifestações culturais." (BRASIL, 1996).

Nessa perspectiva, a formação humana em sua integralidade e, portanto, as relações interpessoais em sua complexidade também são enfatizadas na Base Nacional Comum Curricular - BNCC que estabelece dez competências gerais construídas através de aprendizagens básicas que devem ser adquiridas ao longo da Educação Básica, na complexa interrelação entre cognição e afetividade e estão entrelaçadas as obras de literatura infantil fruto de nossa reflexão.

\section{Narrativas de uma cearense sobre "escrevivências" literárias}

Escrever sobre o letramento literário no processo inicial de escolarização de crianças concebendo-o como ferramenta tecnológica, linguagem humana artística e emancipatória, em tempos de mudança, no atual panorama das políticas de alfabetização no Brasil, a partir da implementação da atual Política Nacional de Alfabetização (2019), é como diria Evaristo (2017) uma "escrevivência", ou seja, é uma escrita que nascida a partir da 
vivência, seja particular ou coletiva, (re)aquece a reflexão crítica entrono da literatura como linguagem artística, a partir da inquietação advinda da práxis.

O olhar hermenêutico para a experiência como componente da formação do professor ao longo da vida me conduziu ao movimento dialético de reflexão-ação-reflexão que marcam os episódios da vida e tecem as composições do percurso formativo de autora nordestina que estabelece diálogos com as infâncias através da literatura infantil.

Minha narrativa, estruturada por uma sequência temporal, traz modos de ser e (re)existir que marcam uma mulher em processo permanente de mudanças e percebendo em cada etapa da vida a complexidade das relações sociais, políticas e econômicas e suas implicações de ser mulher no contexto atual.

É relevante enfatizar que meu percurso de vida e formação como escritora é marcado pelo entendimento de que ser mulher não é apenas uma condição de feminilidade, de aspectos biológicos; ao contrário, é ser sujeito heterogêneo marcado por diferenças, que precisam ser respeitadas dentro de relações democráticas, embora ainda presenciemos em uma sociedade ocidental “pós-moderna', situações de exploração nas mais diversas ordens.

[...] Homens e mulheres estão se distanciando dos modelos estereotipados de gênero e desenvolvendo novas formas de subjetividade, livres do imperativo das divisões traçadas pelas representações sociais" (ARAÚJO, 2005, p.50),

A condição social da mulher na sociedade atual mudou muito desde a chamada Revolução Feminista da década de 1960. Conquistas sociais que hoje soam como naturais eram inimagináveis por exemplo, na sociedade do século XXI, retratada na história de Mary Shelly no filme dirigido por Al Mansour (2017). O filme traz a vida de Mary Wollstonecraft Shelley (1797-1851) escritora do famoso romance Frankenstein (1818) que enfrentou dificuldades para publicação da obra, tendo sido rejeitada por editoras pelo fato de ser mulher. Para a publicação da primeira edição do clássico mundialmente conhecido, houve a supressão do nome da autora e apenas um prefácio escrito por Percy Bysshe Shelley, seu esposo.

No Brasil, com a implantação da imprensa os primeiros exemplares de livros infantis editados no Brasil datam do início do século XIX e eram principalmente em traduções de livros europeus. Nesse cenário, as mulheres escritoras aparecem, ainda de forma tímida, para Teles (2008) isso se deu em decorrência do 'lugar' relegado à mulher no contexto histórico. 
Júlia Lopes de Almeida, escritora, abolicionista brasileira, é considerada pioneira na literatura infantil com o livro Contos Infantis (1886), lançado em coautoria com a irmã.

Em seguida, no século XX, em meio as narrativas marcadas pelos ideais burgueses, pelo moralismo e didatismo literário começa a emergir publicações de mulheres escritoras como Cecília Meireles na década de 1920, Clarice Lispector na década de 1940, Ana Maria Machado na década de 1970, dentre outros nomes que ganham notoriedade no século XX e século XXI quando a literatura infantil se consolida como linguagem humana artística e cultural e se estabelece como dispositivo presente nas políticas públicas de formação de leitores.

Neste cenário, de lutas por relações mais democráticas e no respeito à diferença, em 2010, apanhando desperdícios, como enfatiza Manoel de Barros (2019), usei as palavras para compor os silêncios da criação artística que ganhou voz nas leituras literárias de crianças do Ceará, quando tive lançada minha primeira obra literária: 'As aventuras do Boneco Peteleco ${ }^{2}$. Foi assim que descobri que não tenho voz de canto, mas tenho voz de conto.

O texto de 'As aventuras do Boneco Peteleco' foi aprovado em seleção pública e publicado pela Secretaria de Educação do Estado do Ceará - SEDUC. A obra foi distribuída em todas as Instituições de Educação Infantil do Ceará e escolas com turmas de $1^{\circ}$ e $2^{\circ}$ ano do ensino fundamental. Esse foi o portal de acesso ao universo de produção de um gênero que sempre esteve presente em minha vida ao longo da Educação Básica.

Em meio a mobilização do Governo do Estado do Ceará pela garantia do direito das crianças aprenderem a ler e a escrever até o final dos oito anos de idade, a Secretaria de Educação do Ceará - SEDUC/CE lançou através do Programa Alfabetização na Idade Certa, o Edital PAIC Prosa e Poesia, uma seleção pública cuja finalidade foi a produção de obras literárias por cearenses, com vistas a composição de acervos de coleções literárias para as salas de aula de educação infantil e $1^{\circ}$ e $2^{\circ}$ ano do ensino fundamental de escolas públicas do estado.

A iniciativa contribuiu e ainda contribui para o fortalecimento do letramento literário na infância e publica obras literárias de pessoas de todo o estado que não têm a oportunidade de publicação em grandes editoras que priorizam nomes já ‘consagrados' na literatura. Os autores cujos textos são aprovados recebem premiação em dinheiro e a publicação

\footnotetext{
${ }^{2}$ Obra que traz a história de um Boneco de Pano que viaja por diversos lugares em sua cadeira de rodas. Ilustrado por Débora Cavalcate.
} 
de sua obra, com milhares de tiragens distribuídas em escolas públicas de todo território cearense.

E “porque eu não sou da informática: eu sou da invencionática”, como afirmou Manoel de Barros, em 2012 participei novamente da seleção pública e ganhei mais uma vez o concurso, com a obra 'Sinsalabim, poesia para mim!'.
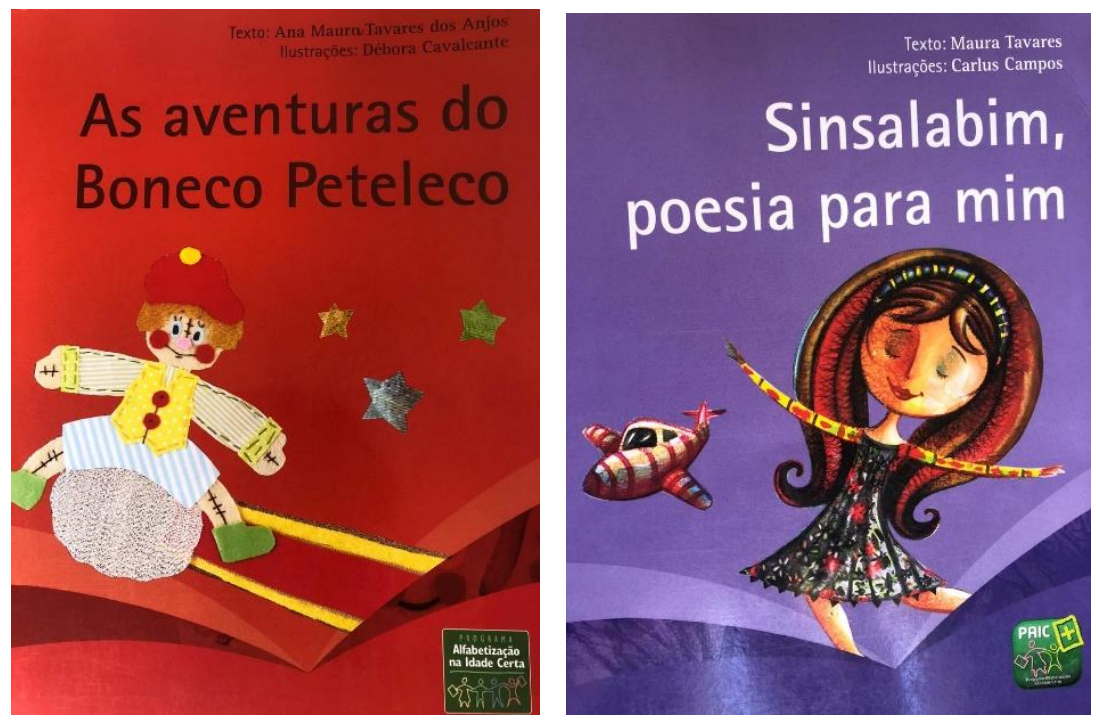

Figura 1: Publicações na Coleção PAIC Prosa e Poesia

Fonte: Arquivo da autora.

A participação nesse processo oportunizado pelo Governo do Ceará foi de grande relevância para que minha escrita ganhasse notoriedade e que eu pudesse, em 2014, assinar contrato com as Edições IPDH, uma editora cearense, para o lançamento de 04 (quatro) livros de literatura infantil, e outas 04 (quatro) obras em 2020.

Os quatro títulos compõem a coleção 'De casa para a Escola' (2014) e fazem parte do Projeto Semeando Valores (2014) que nasce das inquietações advindas do "chão da escola", decorrentes do afastamento substancial da família e diminuição de diálogos favorecedores da construção de valores que solidifiquem a relação entre pais ou outros responsáveis/filhos(as) e a escola.

Desse modo o projeto apresenta, através do trabalho com os títulos da coleção, possibilidades significativas de trabalho no âmbito das relações afetivas e sociais entre família e escola a partir do resgate de valores sine qua non na formação das crianças e no desenvolvimento da leitura literária.

\footnotetext{
${ }^{3}$ Obra reúne 10 (dez) poesias que falam sobre o universo infantil. Ilustrado por Carlos Campos.
} 
A editora tem trilhado caminhos de estabelecimento de vínculos com municípios do Ceará, Maranhão, Piauí, Tocantins, Rio de Janeiro, Pernambuco, Alagoas. Desse modo, o trabalho com os livros transpõe os aspectos do mercado editorial na venda de livros e trabalha com a formação de professores da rede pública (em grade maioria) e da rede privada de ensino. O trabalho com o projeto semeando valores está voltado à formação continuada de professores(as), famílias e crianças.

Os livros que compõem a coleção são: Miga, a minhoca teimosa, Balaio de Gatos, Teco o Tatuzinho, Um Robô no conserto, são caraterizados pela presença do universo imaginário da fantasia. Os personagens que compõe a trama da narrativa são animais, pessoas e brinquedos cujo diálogo criativo permite que os leitores estabeleçam contato com conflitos peculiares da infância, mas que falam à criança por meio do imaginário. A narrativa como representação da realidade possibilita uma compreensão da experiência.

A narrativa do livro Miga, a minhoca teimosa relata a saga de uma minhoquinha curiosa que não segue os conselhos de sua mãe e se envolve em grande perigo. Em Balaio de Gatos, encontramos a história de três gatos que moram em um balaio na casa da Vovó. Um dos gatos apresenta distúrbio de conduta provocando grandes confusões por suas mentiras recorrentes. Já Teco, o tatuzinho precisa de um convívio pautado no diálogo, no acolhimento e na compreensão das dificuldades revelando a afetividade como elemento importante para a formação da personalidade e de elementos como a resiliência e a segurança nas relações. $\mathrm{O}$ Robô no conserto evidencia dificuldades comportamentais de um Robô que necessita de intervenção da família e da escola em colaboração.

Os textos são escritos em prosa (prosa é um texto escrito em parágrafos) e sua forma envolve um vocabulário simples e sintaxe clara. Vale ressaltar que a construção da narrativa também manteve a atenção para a sonoridade e as imagens e sua articulação com o texto. Além disso os textos têm influência da ciência psicológica, com destaque para as questões de construção do juízo moral e da relação entre aspectos da cognição e afetividade que conforme Piaget (1994) apresentam-se como aspectos indissociáveis do funcionamento mental e que, nesse sentido, são percebidos nas narrativas dos textos que compõem a coleção.

A história da literatura infantil já estudada por Coelho (2000) ressalta a presença de aspectos das narrativas atreladas a intencionalidade de ensino de valores, ética e moralidade, o que não quer dizer que os textos da coleção 'De casa para a escola' tenham caráter psicologizante de questões da infância. Outra influência que marca o pensamento da autora é a 
perspectiva sociohistórica de Vygotsky ao ressaltar o papel ativo do ser humano nas relações de sociais e consequentemente na relação com texto.

As ilustrações dos livros favorecem a construção da competência leitora, iniciada pelo despertar do desejo. E o que a criança pode desejar? A criança deseja o que ela vê, aquilo que lhe afeta, que a toca, na experiência de apreciação da arte, dos elementos visuais que compõem a narrativa escrita e que lhe apoia na aquisição gradual da capacidade interpretativa e dos sentidos no texto.
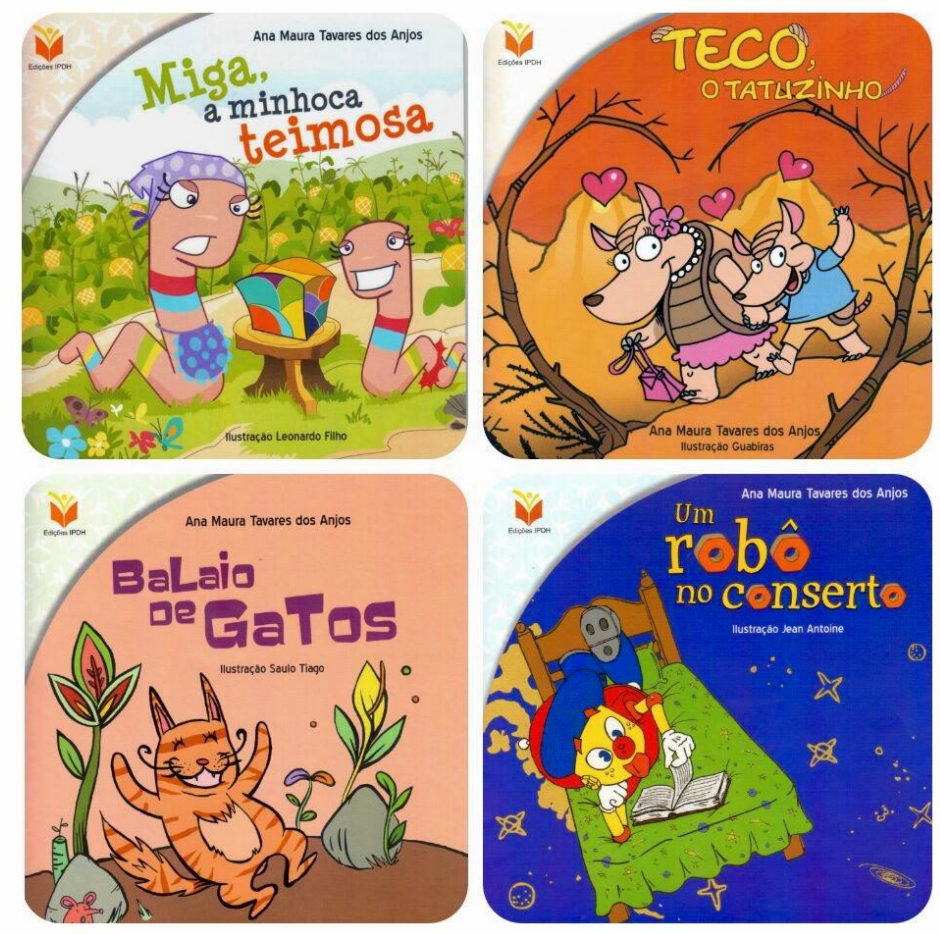

Figura 2: Coleção 'De casa para a escola'

Fonte: Arquivo da autora.

A figura 1 traz um recorte das ilustrações das capas dos livros. A imagem, componente importante para a construção de sentidos pela criança em processo em fase inicial de aquisição do sistema de escrita, permitem ao leitor a apreciação elementos estéticos literários e imagéticos - que ilustram a essência da narrativa, representando-a e complementando-a, além de atrair a atenção dos leitores. realização de inferências a partir de imagens que trazem informações sobre elementos da narrativa escrita.

\section{Considerações provisórias}

Refletir sobre a literatura infantil no contexto da sociedade atual nos conduz a dialogarmos sobre esse gênero do discurso partir de um viés de influências sociológicas uma 
vez que as construções narrativas estão imbricadas que valores sociais, conceitos e modos de vida de um determinado contexto histórico.

A narrativa autobiográfica metareflexiva sobre os saberes da experiência possibilitaram a identificação mnemônica de elementos que evidenciam a importância das políticas públicas para o letramento e para a identificação, valorização e divulgação do trabalho de escritores e artistas, conforme é evidenciado em minha trajetória 'profissional' como escritora, que tem raiz na coleção Prosa e Poesia do PAIC e se solidifica no percurso das publicações das Edições IPDH.

Os livros da coleção, já trabalhado com centenas de crianças em dezenas de municípios cearenses e em outros estados do Brasil como Maranhão e Rio de Janeiro, têm evidenciado a literatura como caminho profícuo para o desenvolvimento do letramento literário, da formação de valores e apontam veredas para o trabalho com o desenvolvimento de habilidades socioemocionais na primeira infância. Além disso marcam o fazer de uma mulherescritora nordestina que encontrou na literatura o caminho para o desenvolvimento do letramento literário e da emancipação no processo de intersubjetivação de consciências.

\section{Referências:}

ALVES, Rubens. Ostra feliz, não faz pérolas. 2. ed. São Paulo: Planeta, 2014.

ANJOS, Ana Maura Tavares dos. Semeando valores na escola e na família; ilustrações de Leonardo Filo et. Al. Fortaleza: Edições IPDH, 2014.

ARAÚJO. Maria de Fátima. Diferença e igualdade nas relações de gênero: revisitando o debate. PSIC. CLIN., Rio de Janeiro, Vol.17, N.2, P.41 - 52, 2005

BARTHES, Roland, 1980. O rumor da língua. 2a ed. São Paulo: Martins Fontes, 2004.

BARTHES, Roland. O Prazer do Texto. São Paulo: Editora Perspectiva, 1987.

BARROS. Manoel. Memórias inventadas. 1ª ed. Rio de Janeiro: Alfaguara, 2018.

BAUMAN, Zygmunt. Amor líquido: Sobre a fragilidade dos laços humanos. Rio de Janeiro: Zahar, 2004.

COELHO, Nelly Novaes. Literatura Infantil: Teoria, análise, didática. $1^{\mathrm{a}}$ Ed. São Paulo: Ed. Moderna, 2000.

BRASIL. Lei de Diretrizes e Bases da Educação Nacional- LDB. 9394/1996. 
BRASIL. Base Nacional Comum Curricular (BNCC). Educação é a Base. Brasília, MEC/CONSED/UNDIME, 2017. Disponível em: < 568 http://basenacionalcomum.mec.gov.br/images/BNCC_publicacao.pdf>. Acesso em: 02 jun. 2019.

COLOMER, Teresa. Andar entre livros: a leitura literária na escola. São Paulo: Global, 2007. EVARISTO. Conceição. Entrevista ao Nexo Jornal. In: LIMA, Juliana Domingos. Conceição Evaristo: 'minha escrita é contaminada pela condição de mulher negra' 26 de maio de 2017. Disponível em:

<https://www.nexojornal.com.br/entrevista/2017/05/26/Concei\%C3\%A7\%C3\%A3o-

Evaristo-\%E2\%80\%98minha-escrita-\%C3\%A9-contaminada-pelacondi\%C3\%A7\%C3\%A3o-de-mulher-negra\%E2\%80\%99 > Acesso em: 27/04/2020.

FREIRE, Paulo. A importância do ato de ler: em três artigos que se completam. São Paulo: Autores Associados: Cortez, 1989.

FREIRE, Paulo. Leitura do mundo, leitura da palavra. $7^{\text {a }}$ ed. Rio de Janeiro: Paz e Terra, 2015.

GOLEMAN, D. Inteligência Emocional. A teoria revolucionária que define o que é ser inteligente. $2^{\mathrm{a}}$ ed. Rio de Janeiro: Objetiva, 2012.

MARY SHALLEY. Direção: Haifaa Al Mansour. Reino Unido, Luxemburgo, EUA, 2017. (120min.)

PASSEGGI, Maria da Conceição. Narrativas da experiência na pesquisa-formação: do sujeito epistêmico ao sujeito biográfico. Roteiro, Joaçaba, v.1, p. 67-86, jan/abr. 2016.

PIAGET, Jean. O juízo moral na criança. São Paulo: Summus, 1994.

REYES, Yolanda. A casa imaginária: leitura e literatura na primeira infância. Global. 2011.

RICOUER, Paul. Interpretação e ideologias. Rio de Janeiro, F. Alves, 1990.

SOARES, Magda (2003) Letramento: um tema em três gêneros. Belo Horizonte: Autêntica, 2003.

TELES, N. Escritoras, escritas, escrituras. In: PRIORE, M. D. (Org.) História das mulheres no Brasil. (9 ed.) São Paulo: Contexto, 2008. p. 401-442. 